\title{
Comparative Evaluation of Treatment Outcome of Gingival Depigmentation by Surgical Scalpel, Laser and Cryosurgery Techniques for the Management of Gingival Hyperpigmentation - A Randomized Clinical Trial Conducted in the Institute of Swargiya Dadasaheb Kalmegh Smruti Dental College and Hospital, Hingna
}

\author{
Saurabh Lingala ${ }^{1}$, Deepti Gattani², Jigyasa Sahu³ ${ }^{3}$ Nupur Kar ${ }^{4}$ \\ 1,2,3,4 Department of Periodontology, Swargiya Dadasaheb Kalmegh \\ Dental College \& Hospital, Nagpur, Maharashtra, India.
}

\section{ABSTRACT}

\section{BACKGROUND}

Aesthetic concerns have plagued humans for ages, but now modern technology and science have presented us with various options to treat these concerns. One such aspect is gingival depigmentation which as a dentist, we often come across. A randomized controlled clinical trial was conducted to compare and evaluate the techniques of gingival depigmentation for the management of gingival hyperpigmentation.

\section{METHODS}

A total of 45 patients with gingival pigmentation were randomly allocated into 3 groups: Surgical scalpel $(\mathrm{N}=15)$, Cryosurgery $(\mathrm{N}=15)$ and $810 \mathrm{~nm}$ Diode Laser $(\mathrm{N}=$ 15). Melanin pigmentation index (MPI), visual analogue scale (VAS), wound healing index (WHI) and colour intensity index were evaluated for all the groups at baseline, immediate postoperative, 1 week, 1 and 3 months postoperatively. Statistical analysis was done for the data obtained to test the significance between the variables. $\mathrm{P}$ value $<0.05$ was considered significant.

\section{RESULTS}

MPI scores from baseline to the postoperative intervals were effective in the management of gingival hyperpigmentation without any statistically significant difference. Faster healing was noted with surgical scalpel than cryosurgery. VAS scores were higher for the surgical scalpel group and lower for the other groups. The colour intensity index, an increase in the red colour value and decrease in the blue colour value was indicative of effectiveness of all the three techniques in the management of gingival hyperpigmentation.

\section{CONCLUSIONS}

It can be concluded that all the three techniques are effective in the management of gingival hyperpigmentation.
Corresponding Author: Dr. Nupur Kar, Swargiya Dadasaheb Kalmegh Smruti Dental College and Hospital, Hingna, Nagpur, Maharashtra, India. E-mail: nupurkar37@gmail.com

DOI: $10.14260 /$ jemds/2021/527

How to Cite This Article:

Lingala S, Gattani D, Sahu J, et al. Comparative evaluation of treatment outcome of gingival depigmentation by surgical scalpel, laser and cryosurgery techniques for the management of gingival hyperpigmentation - a randomized clinical trial conducted in the Institute of Swargiya Dadasaheb Kalmegh Smruti Dental College and Hospital, Hingna. J Evolution Med Dent Sci 2021;10(32):2570-2576, DOI: $10.14260 /$ jemds/2021/527

Submission 12-05-2021,

Peer Review 06-07-2021,

Acceptance 14-07-2021,

Published 09-08-2021.

Copyright (C) 2021 Saurabh Lingala et al. This is an open access article distributed under Creative Commons Attribution License [Attribution 4.0 International (CC BY 4.0)]

\section{KEY WORDS}

Gingival Hyperpigmentation, Aesthetic, Cryosurgery, Surgical Scalpel, Laser 


\section{BACKGROUND}

Aesthetic concerns have directed the management of dental maladies to varying extent for many years. The awareness and expectations of the patients from a dental treatment have increased recently to the point that less-than-optimal aesthetics are no longer an acceptable outcome. ${ }^{1}$ The most common components of mouth that play an essential role in building an attractive face, personal satisfaction and affects confidence are lips, teeth and gingival tissue that are seen when a person smiles or speaks. Therefore, gingival pigmentation affects the beauty of smile.,3 With the growing aesthetic concern, gingival hyperpigmentation although not a medical problem, but may present as a black gum in patients with high smile line. The most common cause of gingival pigmentation is the overproduction of melanin, a brown pigment produced by the melanoblasts. ${ }^{4,5}$ The oldest text by Ginwalla et al. 1966 documented about the unpleasant dark gingival colour and suggested removal of these pigmented areas. ${ }^{6}$

Gingival hyperpigmentation can be treated with various methods which include surgical methods such as gingivectomy, ${ }^{7}$ gingivectomy with free gingival autograft, 8 gingival abrasion technique, ${ }^{9}$ split thickness epithelial excision, ${ }^{10}$ combination technique (gingival abrasion and split thickness epithelial excision) electrosurgery, ${ }^{11}$ chemical methods using phenol, alcohol, ascorbic acid and recent methodologies like lasers, ${ }^{12,13}$ cryosurgery, ${ }^{14}$ and radiosurgery. ${ }^{15}$ Every technique has its own advantages and disadvantages. Therefore, clinical experience, patient's affordability and individual's preferences should dictate the selection of technique. Surgical scalpel technique being the most ancient technique is a recommended method in areas with equipment constraint which may not be readily available at dental clinics. Although the surgical wound created due to scalpel heals rapidly than the other techniques, the unpleasant bleeding during and after the procedure has made the technique less acceptable.

In recent years, lasers have emerged as the most effective, compatible, valid method and choice of treatment among clinicians. Another relatively newer technique of gingival depigmentation that has emerged is cryosurgery which is based on the principle of cryonecrosis of tissues. The use of cryogen tetrafluoroethane (TFE) is easy, practical, and inexpensive as compared to lasers and other conventional methods such as scalpel or chemical methods. The ultra - low temperature of TFE causes controlled cryonecrosis of gingival epithelium and effectively eliminates gingival pigmentation without any significant side effects and aesthetically pleasing results. ${ }^{16}$ There is limited availability of higher level of evidence; the present study has been conducted to compare and evaluate the efficacy of the gingival depigmentation by surgical scalpel, laser, and cryosurgery with TFE.

\section{METHODS}

A randomized comparative clinical trial was conducted after the study protocol was approved by the Institutional Ethics Committee and the approval document had been sent. This study was conducted in the Institute of Swargiya Dadasaheb
Kalmegh Smruti dental college and hospital, Hingna, Nagpur from November 2017 to April 2019. Sample size estimation was done by using G Power software (version 3.0) and a total of 45 patients in the age group of $18-45$ years irrespective of gender were included in this study by estimating the difference between two dependent means in the previous study by Mani A et al. and calculated by the formula $P=65 \%$, for $5 \%$ level of significance $Z_{2 \alpha / 2}=1.96$. wherein an alpha of 0.05 , power of $95 \%, 1.16$ as an effect size was taken into consideration. The individuals were selected from the outpatient department of Periodontics, who requested cosmetic therapy for hampered aesthetics' due to "black gums". Patients with systemically and periodontally healthy condition, with hyperpigmentation extending from the marginal gingiva to mucogingival junction in the maxillary and mandibular arches on the facial aspect from first premolar of left side to the first premolar of opposite side and MPI score equal to 2 were included in the study. Patients with habit of smoking or chewing tobacco in any form, pregnant or lactating females, patients with a previous history of periodontal surgery or taking any medications which causes hyperpigmentation were excluded from the study. Patients were randomly allotted to the treatment group by the lottery method as: Group A - Surgical scalpel $(\mathrm{N}=15)$, Group B Diode Laser ( $N=15)$, Group C - Cryosurgery ( $N=15)$. A detailed case history was recorded; patients were duly explained about the intervention and signed a written informed consent before participation in the study.

\section{Standardization of Photographs}

The patients were made to sit upright in the dental chair with head straight. A Nikon D3200 camera, 24.2 mega pixel digital camera was used for the study. The photos were taken using the golden ratio grid while keeping the central square focused onto the area of pigmentation and keeping the camera stabilized. The images were captured at a resolution of $4032 \times 3024$, shutter speed at $1 / 125$ and ISO of 130 .

\section{Calculation with the Software}

An Adobe Photoshop Software CC (Adobe System, United States) was used to measure the colour intensity (RGB value). The images were cropped and equal size digital grid lines at every $1 \mathrm{~cm}$ were drawn for all images (at baseline, immediately postoperative, 1 week, 1 month and 3 months postoperatively). The pigmented area segments were selected and calculated with regard to the individual red, green and blue values (RGB values) at different intervals of time to calculate the colour intensity.

\section{Detailed Procedure}

All the patients before undergoing any depigmentation procedure underwent phase I periodontal therapy and oral hygiene instructions were given. The patients were then recalled after 7 days and following indices and clinical photographs were taken at baseline and at the follow up intervals:

1. Melanin pigmentation index for gingival pigmentation ${ }^{17}$

2. Wound healing index for wound healing 18

3. Visual analogue scale for assessment of pain ${ }^{19}$ 
4. Colour intensity using image analysis software (Adobe Photoshop CC)

\section{Surgical Scalpel Procedure}

Following local anaesthesia, hyperpigmented areas were treated by using either 15 no. or 11 no. scalpel blades by scraping over the pigmented tissues till there was complete removal of the epithelium along with a small amount of connective tissue. While doing so precautions were taken not to expose the underlying bone. The interdental pigmented tissue was removed using Castro Viejo scissor. The raw surface was irrigated with saline solution. Following haemostasis, the exposed depigmented gingival surface was covered with a periodontal dressing for one week.

\section{Diode Laser}

Diode laser (Picasso, AMD Laser Technologies, USA; wavelength $810 \mathrm{~nm}$ ) set at a power of $0.8 \mathrm{~W}, 400 \mu \mathrm{m}$ fibre, in a continuous irradiation mode was used for deepithelialization procedure. Following application of topical anaesthesia and abiding all the laser safety protocols, the laser tip held in contact with the gingiva and ablation was performed using light paint brush strokes in an apico-coronal direction and on the papillary edges. After the removal of the overlying epithelial tissue, power setting was increased to 1.2 $\mathrm{W}$ so as to ablate remaining pigments present deep beneath the basement membrane with respect to the interdental papillary areas and also to minimize the intraoperative haemorrhage from the connective tissue. After every 3 - 5 min. the surgical field was wiped with sterile gauze soaked in cold saline so as to remove any remnants left out by laser ablation. Ventilation with suction was maintained throughout the procedure. No periodontal pack was given.

\section{Cryosurgery Technique}

Following application of topical anaesthesia, after drying and isolation of the hyperpigmented area, the tetrafluoroethane gas was dispensed using the valve and nozzle over dry cotton swabs and then immediately gently rolled over the hyperpigmented tissue including the gingival papillae. A freezing zone was maintained continuously for $30-40$ seconds in each area till thawing of the tissues was visible which faded after 10 - 15 seconds. No periodontal dressing was given.

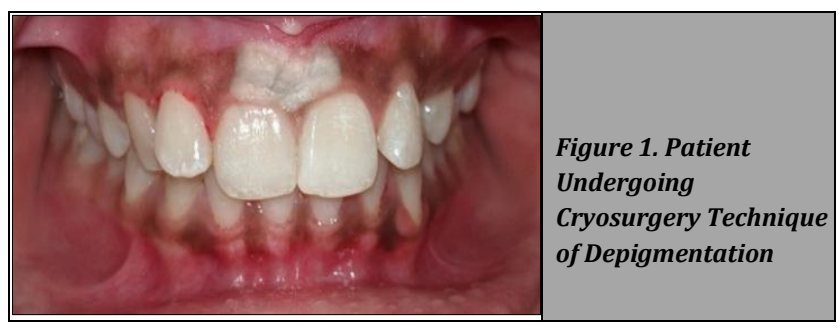

\section{Postoperative Instructions}

- Patients were advised not to eat acidic, salty, hot and spicy foods for the first few days after operation.
- They were instructed to maintain good oral hygiene and avoiding trauma to the surgical site.

- They were prescribed with analgesics only to be taken in case of pain and $0.2 \%$ chlorhexidine gluconate mouthwash to be rinsed twice daily for two weeks.

The periodontal dressing was removed at the end of one week for Group A. The patients were recalled after 1 week, 1 month and 3 months post-operatively for follow-up to revaluate and record the parameters and reinforce oral hygiene.

\section{Statistical Analysis}

The data analysis was done using GraphPad Prism version 8.0. Descriptive statistics like mean, median \& standard deviation were used to summarize categorical variables in all the groups. Differences in the mean across the groups were tested by Mann Whitney Signed Rank test while the differences in percentages were tested by Kruskal Wallis test. The $\mathrm{P}$ value $<0.05$ was considered statistically significant. Evaluation and comparison of the groups were titled as intergroup changes. The $\mathrm{CI}$ values were analysed using One Way ANOVA test.

\section{RESULTS}

\section{Melanin Pigmentation Index (MPI)}

Intergroup Changes

Table 1 shows comparison of changes in MPI scores at baseline, immediate postoperative, 1 week, 1 month and 3 months. The intergroup comparison showed statistically significant difference $(\mathrm{P}=0.001)$ at immediate postoperative for group C with score 2 for $100 \%$ of patients. However, no statistically significant difference was observed at 1 week ( $P$ $=0.85), 1$ month $(P=0.95)$ and 3 months $(P=0.90)$ postoperatively.

\begin{tabular}{|c|c|c|c|c|c|c|}
\hline & 吾 & i & 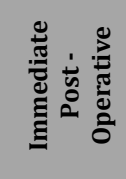 & 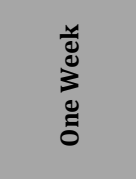 & 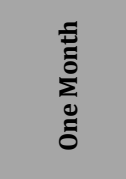 & 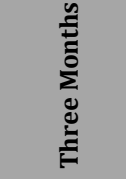 \\
\hline \multirow{4}{*}{$\begin{array}{l}\text { Scalpel } \\
\text { Group }\end{array}$} & 0 & $0(0 \%)$ & $15(100 \%)$ & 13(86.7 \%) & $12(80 \%)$ & $12(80 \%)$ \\
\hline & 1 & $0(0 \%)$ & $0(0 \%)$ & $2(13.3 \%)$ & $3(20 \%)$ & $3(20 \%)$ \\
\hline & 2 & $15(100 \%)$ & $0(0 \%)$ & $0(0 \%)$ & $0(0 \%)$ & $0(0 \%)$ \\
\hline & Total & $15(100 \%)$ & $15(100 \%)$ & $15(100 \%)$ & $15(100 \%)$ & $15(100 \%)$ \\
\hline \multirow{4}{*}{$\begin{array}{l}\text { Diode } \\
\text { Laser } \\
\text { Group }\end{array}$} & 0 & $0(0 \%)$ & $15(100 \%)$ & $13(86.7 \%)$ & $13(86.7 \%)$ & $13(86.7 \%)$ \\
\hline & 1 & $0(0 \%)$ & $0(0 \%)$ & $2(13.3 \%)$ & $2(13.3 \%)$ & $2(13.3 \%)$ \\
\hline & 2 & $15(100 \%)$ & $0(0 \%)$ & $0(0 \%)$ & $0(0 \%)$ & $0(0 \%)$ \\
\hline & Total & $15(100 \%)$ & $15(100 \%)$ & $15(100 \%)$ & $15(100 \%)$ & $15(100 \%)$ \\
\hline \multirow{4}{*}{$\begin{array}{l}\text { Cryo- } \\
\text { surgery } \\
\text { Group }\end{array}$} & 0 & $0(0 \%)$ & $0(0 \%)$ & 13(86.7 \%) & $13(86.7 \%)$ & 12(80 \%) \\
\hline & 1 & $0(0 \%)$ & $0(0 \%)$ & $2(13.3 \%)$ & $2(13.3 \%)$ & $3(20 \%)$ \\
\hline & 2 & $15(100 \%)$ & $15(100 \%)$ & $0(0 \%)$ & $0(0 \%)$ & $0(0 \%)$ \\
\hline & Total & $15(100 \%)$ & $15(100 \%)$ & $15(100 \%)$ & $15(100 \%)$ & $15(100 \%)$ \\
\hline \multicolumn{2}{|c|}{$\chi^{2}$ - value } & - & 45 & 0.00 & 0.33 & 0.30 \\
\hline \multicolumn{2}{|c|}{$\mathrm{p}$-value } & - & $0.0001, S$ & $1.00, \mathrm{NS}$ & $0.84, \mathrm{NS}$ & $0.85, \mathrm{NS}$ \\
\hline \multicolumn{7}{|c|}{$\begin{array}{l}\text { Table 1. Representing Intergroup Comparison (Group A, B and C) of } \\
\text { Melanin Pigmentation Index (MPI) Scores at Follow Up Intervals }\end{array}$} \\
\hline
\end{tabular}

\section{Wound Healing Index (WHI)}

Intergroup Changes

Table 2 shows comparison of changes in WHI scores at baseline, immediate postoperative, 1 week, 1 month and 3 
months. Immediate postoperative score was statistically significant for all the groups (Score C for Group A and B and Score A for Group C, $(\mathrm{P}=0.0001)$. Also, the score after 1 week was statistically significant for all the groups $(\mathrm{P}=0.0001)$, but the score at 1 month $(\mathrm{P}=0.25)$ and 3 months was not statistically significant between the three groups.

\begin{tabular}{|c|c|c|c|c|c|c|}
\hline & $\begin{array}{c}\text { Wound } \\
\text { Healing } \\
\text { Index }\end{array}$ & $\begin{array}{l}\text { Pre - } \\
\text { Operative }\end{array}$ & $\begin{array}{c}\text { Immediate } \\
\text { Post - } \\
\text { Operative }\end{array}$ & One Week & $\begin{array}{c}\text { One } \\
\text { Month }\end{array}$ & $\begin{array}{c}\text { Three } \\
\text { Months }\end{array}$ \\
\hline \multirow{4}{*}{$\begin{array}{l}\text { Scalpel } \\
\text { Group }\end{array}$} & A & $15(100 \%)$ & $0(0 \%)$ & $12(80 \%)$ & $15(100 \%)$ & $15(100 \%)$ \\
\hline & B & $0(0 \%)$ & $0(0 \%)$ & $3(20 \%)$ & $0(0 \%)$ & $\%)$ \\
\hline & $\mathrm{C}$ & & 15( & & & \\
\hline & Total & $15(1$ & & & $15(1$ & \\
\hline \multirow{4}{*}{$\begin{array}{l}\text { Diode } \\
\text { Laser } \\
\text { Group }\end{array}$} & A & $15(100 \%)$ & & $8(5$ & $15(1$ & $15(100 \%)$ \\
\hline & B & $0(0 \%)$ & $0(0$ & $5(33.33 \%)$ & $0(0 \%)$ & $0(0 \%)$ \\
\hline & C & & & & & \\
\hline & Total & $15(1$ & & 15( & $15(1$ & \\
\hline \multirow{4}{*}{$\begin{array}{l}\text { Cryo- } \\
\text { surgery } \\
\text { Group }\end{array}$} & A & $15(100 \%)$ & $15(1$ & $0(0 \%)$ & $14(93$. & $15(10$ \\
\hline & B & $0(0 \%)$ & $0(0 \%)$ & $7(46.67 \%)$ & $1(6.67 \%)$ & $0(0 \%)$ \\
\hline & $\mathrm{C}$ & $0(0$ & $0(100$ & $8(53.33 .67 \%)$ & $0(0 \%)$ & $0(0 \%)$ \\
\hline & Total & $15(100)$ & $15(1$ & 15 & $15(1$ & $15(1$ \\
\hline \multicolumn{2}{|c|}{$\chi 2$ - value } & - & 30 & 45 & 2.0 & - \\
\hline$p-1$ & value & - & $0.0001, \mathrm{~S}$ & $0.0001, \mathrm{~S}$ & $0.35, \mathrm{NS}$ & - \\
\hline \multicolumn{7}{|c|}{$\begin{array}{l}\text { Table 2. Representing Intergroup Comparison (Group A, B and C) of } \\
\text { Wound healing Index Scores at Follow Up Intervals }\end{array}$} \\
\hline
\end{tabular}

\section{Visual Analog Scale}

Intergroup Changes

Graph 1 depicts the intergroup comparison of VAS scores. Immediate postoperatively, statistically significant variation was observed across the group $(P=0.0001)$ and also in between group $\mathrm{A}$ and $\mathrm{B}(\mathrm{P}=0.0001)$, group $\mathrm{A}$ and $\mathrm{C}(\mathrm{P}=$ $0.0001)$ and between group $B$ and $C(P=0.029)$. At 1 week postoperative, statistically significant variation was observed across the group $(\mathrm{P}=0.0001)$ and also between group $\mathrm{A}$ and $B(P=0.0001)$, group $A$ and $C(P=0.201)$ and group $B$ and $C$ $(\mathrm{P}=0.0001)$. However, no statistically significant difference was observed at 1 month and 3 months postoperatively between the groups.

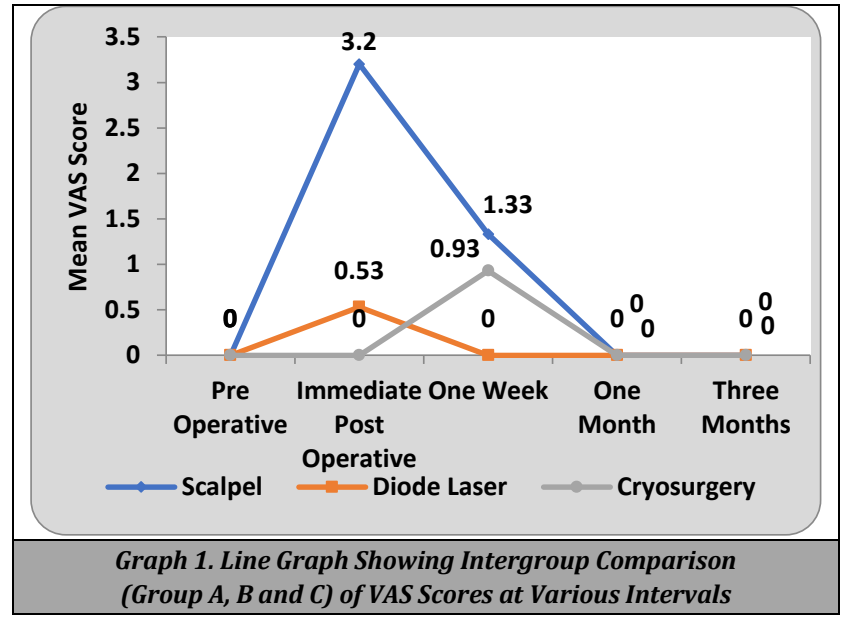

\section{Colour Intensity Index}

Intergroup Changes (Red Colour)

Graph 2 depicts intergroup comparison of colour intensity index for red colour. For immediate postoperative scores, a statistically significant difference was recorded across the group ( $F=1304.84, P=0.0001)$ and in between the groups [Group A and B (P = 0.0001), Group A and C (P=0.0001) and between Group B and C ( $P=0.029)]$. No significant difference was recorded at 1 week, 1 month and at 3 months across the group and in between the groups.

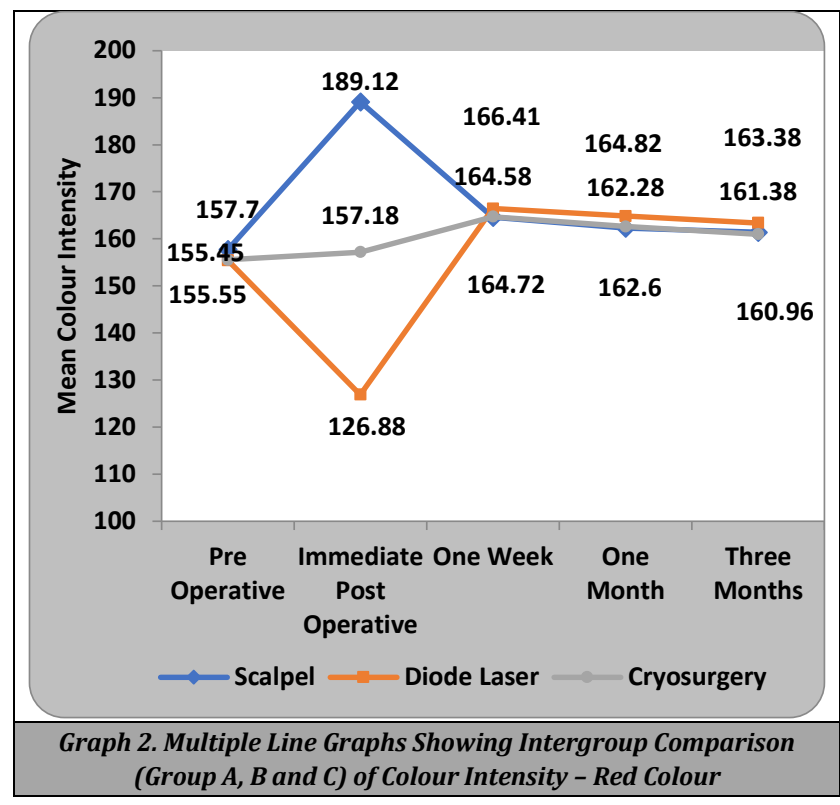

\section{Intergroup Changes (Green Colour)}

No significant difference was observed preoperatively and immediate postoperatively across the group and in between the groups. However, at one week $(F=0.20, P=0.81)$ no significant difference was observed across the group and in between the groups. At one month postoperatively, significant difference was observed across the group $(\mathrm{F}=$ 5.34, $\mathrm{P}=0.009$ ) and no significant difference was recorded between group $A$ and $B(P=1.000)$, but significant differences were seen between group $A$ and $C(P=0.048)$ and also between group $B$ and $C(P=0.011)$.

\section{Intergroup Changes (Blue Colour)}

A statistically significant difference was observed at immediate postoperative between group A and $C$ (0.0001) and between group $B$ and $C(P=0.0001)$. No significant difference was seen at 1 week, 1 month and 3 months postoperatively.

\section{DISCUSSION}

Hyperpigmentation may be observed in all races and at all ages with no gender predilection ${ }^{20}$ and interferes with an individual's smile window. With the increasing awareness among the patient for the aesthetics', there has been a surge in the treatment modalities for hyperpigmentation. To the best of the author's knowledge, no study has been conducted previously comparing the efficacies of three treatment modalities - Surgical scalpel, diode laser and cryosurgery technique. In the present study, no significant difference was observed in between the groups for any of the investigated parameters indicative of appropriate patient selection and devoid of bias. Also, during the course of study wound healing was uneventful for every patient in all the groups without any sign of infection or complications. 


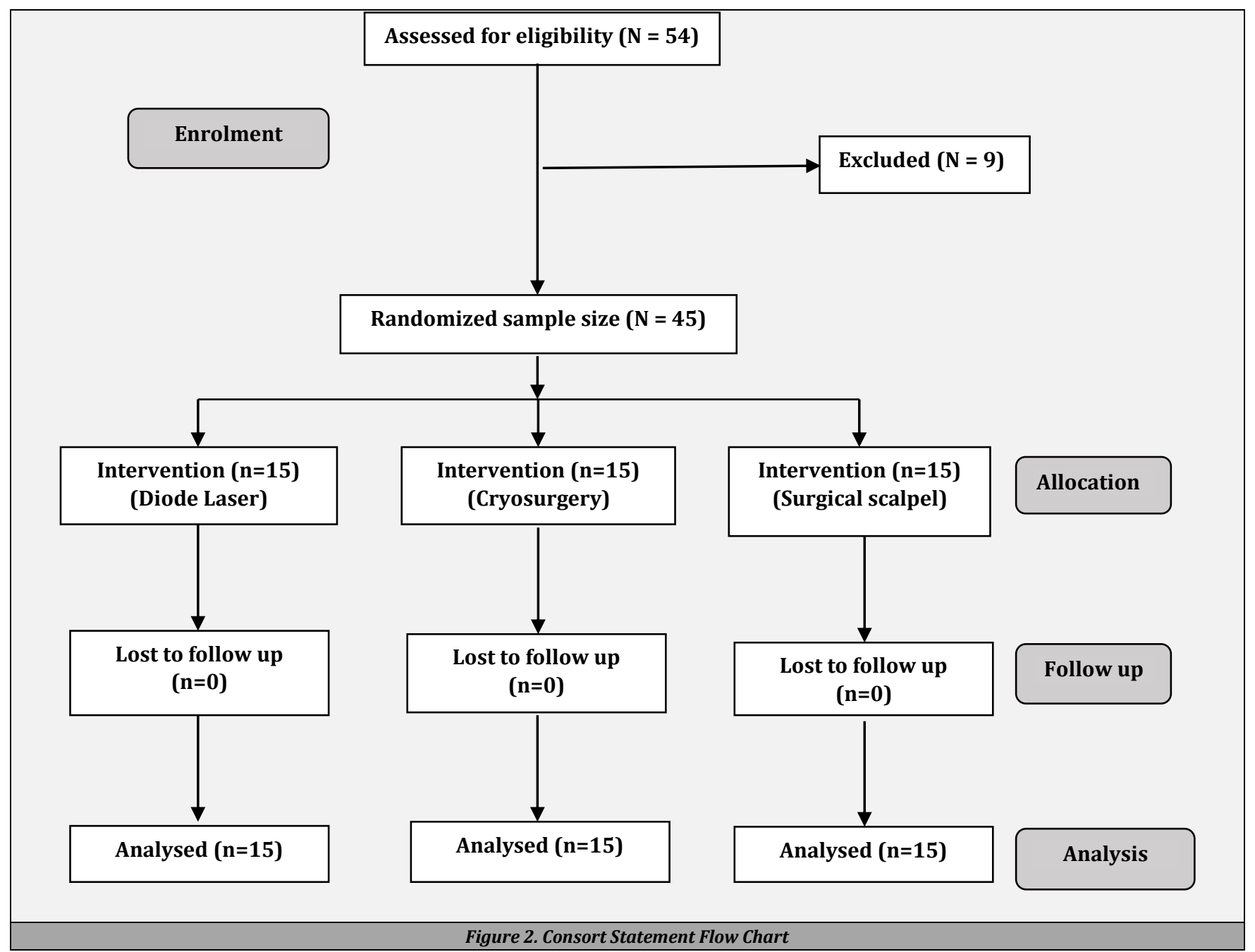

\section{Pigmentation Index}

The present study showed a significant reduction in MPI score at immediate postoperative for group A and B owing to the complete removal of the epithelium along with a thin layer of connective tissue and melanin pigments. These findings were in accordance with the studies conducted by the Ambika Bharadwaj et al. (2014) 21,22,23

\section{Repigmentation}

It has been a critical concern in the treatment of hyperpigmentation. Although, duration of repigmentation differs from one technique to another it has remained controversial, various factors such as smoking, sun exposure, and genetic determination of skin colour, influence the duration of relapse. Repigmentation may be attributed to the migration of the melanocytes which are left during the surgery as stated by the Ginwalla et al. ${ }^{24}$ or due to the migration of the active melanocytes from the adjacent pigmented tissue to the treated site as stated by the migration theory. ${ }^{25}$ The present study reported, no significant difference between the three techniques yet group A had a higher rate of recurrence.

The probable cause of repigmentation in group A may be attributed to incomplete removal of melanocytes from the deeper layers of the gingival tissue and also the difficulty to visualize the complete removal of melanocytes due to bleeding. With regards to group $\mathrm{B}$, the near proximity of papillary and marginal gingiva to the tooth surface restricts the application of diode laser so as to avoid damage to the tooth structure. For group C, repigmentation could be attributed to difficulty in controlling the depth of penetration, optimal duration of freezing is not known and also no immediate changes were observed that this technique could leave behind residual pigments.

\section{Wound Healing Index}

The present study revealed statistically significant difference in the wound healing index at 1 week postoperatively with better healing potential in group A than group B and C. The findings are consistent with the findings of Lagdive et al. $(2009)^{26}$ and D'Arcangelo et al. (2007) ${ }^{27}$ who reported delayed healing in diode laser treated sites. Luomanen et al. $(1987)^{28}$ connoted that with lasers, there is retarded proliferation of capillaries and slower infiltration of inflammatory cells due to thermal coagulation and denaturation of vasculogenic polypeptides.

On the contrary, Fisher et al. (1983), ${ }^{29}$ Gnana Sagar (2016),30 LT Hariati et al. (2018),31 reported rapid healing with lasers as compared to the surgical counterpart due to the photobiostimulatory effect or low-level laser therapy effect which increases the proliferation of fibroblasts, 
increased synthesis of proteins and reduced bacteraemia due to reactive oxygen species.

\section{Visual Analog Scale}

The present study revealed significantly increased pain perception by the patients of group A, slight or negligible pain for group $B$ whereas no patients in group $C$ reported any pain $(\mathrm{P}=0.0001)$. Increased pain perception in group $\mathrm{A}$ was due to increased depth of penetration into the connective tissue which exposes lamina propria leaving behind raw wound surface with open nerve ending and healing by secondary intention. $25,32,33,34,35$

In group $B$, lesser pain perception was due to the disruption of sodium - potassium pump in the cell membrane resulting in impaired nerve conduction due to ablation of nerve endings by protein coagulation which also acts as biological dressing thus sealing off free nerve endings. Also, due to photobiostimulation, there is increase in antiinflammatory effects due to neuro hormonal response by serotonin and norepinephrine. $29,36,37,21,22,23,37,38,39$

In group $\mathrm{C}$, the level of pain associated was less than surgical scalpel, however some amount of pain was experienced due to the cellular destruction by rapid freezing and slow thawing of cells. Also, there was slight burning or discomfort after 24 - 72 hours due to immediate blockage of neural transmission in treatment area. ${ }^{25,40}$

\section{Colour Intensity Index}

Colour intensity index measures the RGB (Red, Green, Blue) components in digital images. Red colour represents the haemoglobin while green and blue colour represent cytoplasm and the melanin pigment respectively. There was no significant difference between the RGB values in the intergroup comparison groups but within individual groups there was a significant difference noted in the red, green and blue colour values when compared with the baseline values.

Group A measured increase in red colour due to the extravasation of haematopoietic cells at immediate postoperative while a decrease in red colour was seen in group B which may be due to ablation of capillaries and blood vessels less than $0.5 \mathrm{~mm}$ which gives a dry field due to the effect of diode laser and no changes were observed in group $\mathrm{C}$ as no immediate changes were observed after cryosurgery. Also, the blue colour values reduced significantly when compared with the baseline indicating that all the three techniques, were effective in management of gingival pigmentation.

\section{CONCLUSIONS}

With an increasing aesthetic concern, there is a surge in the demand for depigmentation therapy in patients with excessive gingival display. Although many techniques have been developed till date but a novel technique that has been widely accepted and can wisely treat the smile window of the patient is yet to be evidenced in the literature. In the present study all the three techniques have been shown to be effective in the treatment of hyperpigmentation, but pain perception and recurrence were lesser for both laser and cryosurgery groups. The authors recommend conduct of more prospective randomized controlled longitudinal studies to evaluate the effectiveness of the available techniques with histological evaluation to assess the alteration in the melanin pigment at the molecular level and a longer follow up of 18 36 months to determine the recurrence amongst the techniques.

Data sharing statement provided by the authors is available with the full text of this article at jemds.com.

Financial or other competing interests: None.

Disclosure forms provided by the authors are available with the full text of this article at jemds.com.

\section{REFERENCES}

[1] Morley J. The role of cosmetic dentistry in restoring a youthful appearance. J Am Dent Assoc 1999;130(8):1166-72.

[2] Bakhshi M, Rahmani S, Rahmani A. Lasers in esthetic treatment of gingival melanin hyperpigmentation: a review article. Lasers Med Sci 2015;30(8):2195-203.

[3] Van Der Geld P, Oosterveld P, Van Heck G, et al. Smile attractiveness. Self-perception and influence on personality. Angle Orthod 2007;77(5):759-65.

[4] Azzeh M. Treatment of gingival hyperpigmentation by erbium-doped: yttrium, aluminum and garnet laser for esthetic purposes. J Periodontol 2007;78(1):177-87.

[5] Raposo G, Marks MS. Melanosomes--dark organelles enlighten endosomal membrane transport. Nat Rev Mol Cell Biol 2007;8(10):86-97.

[6] Kaur H, Jain S, Sharma RL. Duration of reappearance of gingival melanin pigmentation after surgical removal-a clinical study. J Indian Soc Periodontol 2010;14(2):1015.

[7] Bergamaschi 0, Kon S, Doine AI, et al. Melanin repigmentation after gingivectomy: a 5-year clinical and transmission electron microscopic study in humans. Int J Periodontics Restorative Dent 1993;13(1):85-92.

[8] Tamizi M, Taheri M. Treatment of severe physiologic gingival pigmentation with free gingival autograft. Quintessence Int 1996;27(8):555-8.

[9] Shimada Y, Tai H, Tanaka A, et al. Effects of ascorbic acid on gingival melanin pigmentation in vitro and in vivo. J Periodontol 2009;80(2):317-23.

[10] Dummett CO, Bolden TE. Postsurgical clinical repigmentation of the gingiva. Oral Surg Oral Med Oral Pathol 1963;16(3):353-65.

[11] Gnanasekhar JD, Al-Duwairi YS. Electrosurgery in dentistry. Quintessence international 1998;29(10):64954.

[12] Gupta G. Management of gingival hyperpigmentation by semiconductor diode laser.J Cutan Aesthet Surg 2011;4(3):208-10.

[13] Allen EP, Gladkova ND, Fomina YV, et al. Successful gingival depigmentation with laser-patterned microcoagulation: a case report. Clin Adv Periodontics 2011;1(3):210-4.

[14] Mayers PD, Tussing G, Wentz FM. The histological reaction of clinically normal gingiva to freezing. J Periodontol 1971;42(6):346-52. 
[15] Bishop K. Treatment of unsightly oral pigmentation: a case report. Dent Update 1994;21(6):236-7.

[16] Yadav R, Deo V, Kumar P, et al. Influence of environmental tobacco smoke on gingival pigmentation in schoolchildren. Oral Health Prev Dent 2015;13(5):407-10.

[17] Hanioka T, Tanaka K, Ojima M, et al. Association of melanin pigmentation in the gingiva of children with parents who smoke. Pediatrics 2005;116(2):e186-90.

[18] Tal H, Stahl SS. Elimination of epithelium from healing postsurgical periodontal wounds by ultralow temperature: initial observations. J Periodontol 1985;56(8):488-91.

[19] Mani A, Mani S, Shah S, et al. Management of gingival hyperpigmentation using surgical blade, diamond bur and diode laser therapy: a case report. Journal of Oral Laser Applications 2009;9(4):227.

[20] Kaya GŞ, Yavuz GY, Sümbüllü MA, et al. A comparison of diode laser and Er: YAG lasers in the treatment of gingival melanin pigmentation. Oral Surg Oral Med Oral Pathol Oral Radiol 2012;113(3):293-9.

[21] Bhardwaj A, Uppoor AS, Naik DG. A comparative evaluation of management of melanin pigmented gingiva using a scalpel and laser. Journal of Interdisciplinary Dentistry 2014;4(3):135-9.

[22] Butchibabu K, Koppolu P, Tupili MK, et al. Comparative evaluation of gingival depigmentation using a surgical blade and a diode laser. Journal of Dental Lasers 2014;8(1):20-5.

[23] Grover HS, Dadlani H, Bhardwaj A, et al. Evaluation of patient response and recurrence of pigmentation following gingival depigmentation using laser and scalpel technique: a clinical study. J Indian Soc Periodontol 2014;18(5):586-92.

[24] Ginwalla TM, Gomes BC, Varma BR. Surgical removal of gingival pigmentation. J Indian Dent Assoc 1966;38(6):147-50.

[25] Ozbayrak S, Dumlu A, Ercalik-Yalcinkaya S. Treatment of melanin-pigmented gingiva and oral mucosa by $\mathrm{CO} 2$ laser. Oral Surg Oral Med Oral Pathol Oral Radiol Endodontol 2000;90(1):14-5.

[26] Lagdive S, Doshi Y, Marawar PP. Management of gingival hyperpigmentation using surgical blade and diode laser therapy: a comparative study. J Oral Laser Applications 2009;9(1):41-7.

[27] D'Arcangelo C, Di Nardo Di Maio F, Prosperi GD, et al. A preliminary study of healing of diode laser versus scalpel incisions in rat oral tissue: a comparison of clinical, histological and immunohistochemical results. Oral Surg Oral Med Oral Pathol Oral Radiol Endodontol 2007;103(6):764-73.

[28] Luomanen M. A comparative study of healing of laser and scalpel incision wounds in rat oral mucosa. Scand J Dent Res 1987;95(1):65-73.
[29] Fisher SE, Frame JW, Browne RM, et al. A comparative histological study of wound healing following $\mathrm{CO} 2$ laser and conventional surgical excision of canine buccal mucosa. Arch Oral Biol 1983;28(4):287-91.

[30] Sagar G, Rajesh N, Kumar TS, et al. Comparative evaluation of two surgical techniques using conventional scalpel method and diode laser for treatment outcome of depigmentation: 6 months follow-up study. Journal of Dental Lasers 2016;10(1):2.

[31] Hariati LT, Sunarto H, Sukardi I. Comparison between diamond bur and diode laser to treat gingival hyperpigmentation. Journal of Physics 2018;1073(6):062020.

[32] Urmi D, Jasuma RJ, Deepak D, et al. Comparison of patient perception on gingival depigmentation using scalpel and diode laser. J Dent Med Sci 2013;11(4):33-8.

[33] Hegde R, Padhye A, Sumanth S, et al. Comparison of surgical stripping; erbium-doped: yttrium, aluminum and garnet laser; and carbon dioxide laser techniques for gingival depigmentation: a clinical and histologic study. J Periodontol 2013;84(6):738-48.

[34] Suragimath G, Lohana MH, Varma S. A split mouth randomized clinical comparative study to evaluate the efficacy of gingival depigmentation procedure using conventional scalpel technique or diode laser. J Lasers Med Sci 2016;7(4):227-32.

[35] Bakutra G, Shankarapillai R, Mathur L, et al. Comparative evaluation of diode laser ablation and surgical stripping technique for gingival depigmentation: a clinical and immunohistochemical study. Int $J$ Health Sci 2017;11(2):51-8.

[36] Kaya GȘ, Yavuz GY, Sümbüllü MA, et al. A comparison of diode laser and Er: YAG lasers in the treatment of gingival melanin pigmentation. Oral Surg Oral Med Oral Pathol Oral Radiol 2012;113(3):293-9.

[37] El Shenawy HM, Nasry SA, Zaky AA, et al. Treatment of gingival hyperpigmentation by diode laser for esthetical purposes. Open Access Maced J Med Sci 2015;3(3):44754.

[38] Chandna S, Kedige SD. Evaluation of pain on use of electrosurgery and diode lasers in the management of gingival hyperpigmentation: a comparative study. J Indian Soc Periodontol 2015;19(1):49-55.

[39] Hariati LT, Sunarto H, Sukardi I. Comparison between diamond bur and diode laser to treat gingival hyperpigmentation. Journal of Physics 2018;1073(6):062020.

[40] Rahmati S, Darijani M, Nourelahi M. Comparison of surgical blade and cryosurgery with liquid nitrogen techniques in treatment of physiologic gingival pigmentation: short term results. J Dent 2014;15(4):1616. 